\title{
Force measurements on storm walls due to overtopping waves: a middle-scale model experiment
}

\author{
Koen Van Doorslaer ${ }^{1}$, Alessandro Romano ${ }^{2}$, Giorgio Bellotti ${ }^{3}$, Corrado Altomare, \\ Iván Cáceres ${ }^{5}$, Julien De Rouck ${ }^{1}$, Leopoldo Franco ${ }^{3}$ and Jentsje van der Meer ${ }^{6}$ \\ ${ }^{1}$ Dept. of Civil Eng., Ghent University, Technologiepark 904, 9052 Zwijnaarde, \\ Belgium; email: koenvandoorslaer@gmail.com, j.derouck@hotmail.com \\ 2 “Sapienza” University of Rome, DICEA, Via Eudossiana, 18, 00184 Roma, Italy; \\ email: alessandro.romano@uniroma1.it \\ ${ }^{3}$ Rome Tre University, Engineering Department, Via V. Volterra 62, 00146 Roma, \\ Italy; email: giorgio.bellotti@uniroma3.it, leopoldo.franco@uniroma3.it \\ 4 Flanders Hydraulics Research, Berchemlei 115, 2140 Antwerpen-Borgerhout, \\ Belgium. Corrado.altomare@mow.vlaanderen.be \\ ${ }^{5}$ Universitat Politècnica de Catalunya, Calle Jordi Girona 31, 08034 Barcelona, \\ Spain; email: i.caceres@upc.edu \\ ${ }^{6}$ Van der Meer Consulting b.v., PO Box 11, 8491 AA, Akkrum; and UNESCO-IHE, \\ Delft, Netherlands, jm@vandermeerconsulting.nl
}

\section{ABSTRACT}

The so-called post-overtopping processes are of wide interest for coastal engineers. Dedicated middle-scale tests have been carried out to measure impacts of an overtopped wave on a storm wall at low freeboard coastal structures. A smooth dike slope and a vertical wall, both with a promenade at crest level and a storm wall at the end of it, have been tested in a scale of 1/6. Impacts have been measured both with pressure and force transducers; the two systems provided similar results. A correlation between the hydraulic conditions and the wave impacts on the storm wall is proposed. Further analysis is ongoing to also include the post-overtopping characteristics to increase insight on the acting parameters in this process.

\section{INTRODUCTION}

Many European researchers have studied overtopping over coastal structures. PROVERBS, OPTICREST and CLASH are three European funded research projects, which gathered a lot of data and knowledge about overtopping over different geometries. This all has cumulated into the EurOtop Overtopping Manual (EurOtop, 2007), and an update with the newest information on wave overtopping will be published in 2016. But what is the damage that can occur due to overtopping waves? This was studied and documented less in the past, but has shown increased interest in the last few years by coastal engineers. The Wave Overtopping Simulator (Van der Meer et al., 2010) tested the stability of the landward side of overtopped (mostly grass or clay) dikes in situ on real scale. But what happens when waves overtop a sea dike or harbor quay wall with a promenade at crest level and where buildings are present? In this paper, we are investigating this post-overtopping behavior. 
Safety assessment studies show that in many countries several zones in coastal defenses have too low freeboards. An example of this are the quay walls in the harbor of Oostende (Belgium) and surrounding coastal areas. Similar situations exist in Vietnam, the Netherlands and many other countries, especially with tidal seas. Often there is no space for extension of the flood defense, which leads to solutions with storm walls or strengthening the walls of existing buildings (see Figure 1).

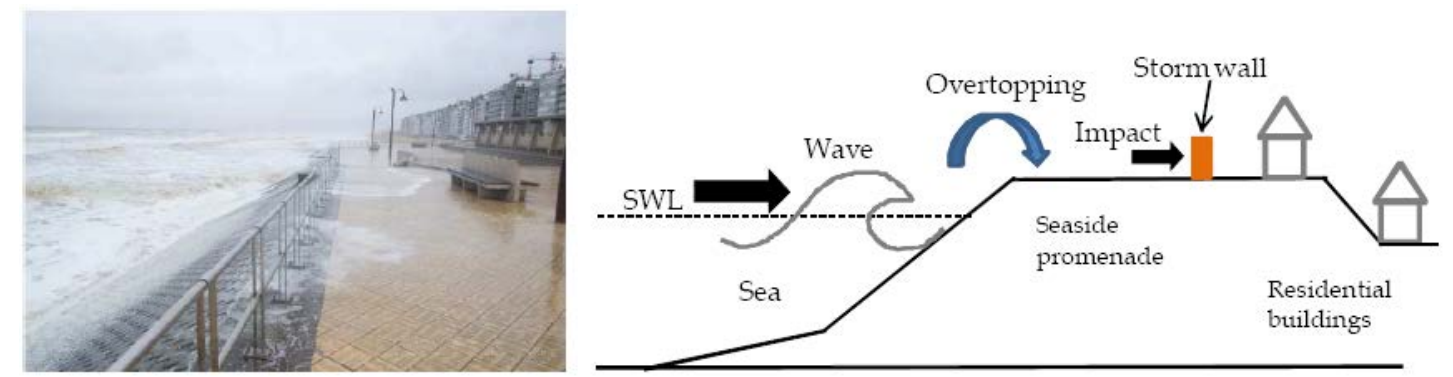

Figure 1. Typical Belgian coast before safety measures were implemented (left), solution with storm wall, impacted by an overtopping bore (right)

In these conditions the waves overtop the quay wall or dike slope and the overtopped bore rushes along the promenade. Finally it hits a (storm) wall or a building. Apart from Chen at al. (2015), not a lot of information exist on the impact forces caused by this kind of overtopped waves.

In our research middle scale model tests have been carried out in July and September 2013 at the CIEM large wave flume, UPC (Barcelona, Spain), within the HYDRALAB IV framework, with the aim of gathering data on impact forces on storm walls, suitable to derive an engineering prediction method. This paper gives an overview of the experimental campaign as well as a description of the experimental set-up and of the measurement devices used in the laboratory. The analysis hasn't been finalized yet, but some experimental formulae to calculate impact forces on storm walls have already been obtained and are presented in the paper.

\section{EXPERIMENTAL SET-UP}

The tests have been carried out in the large wave flume, namely Canal d'Investigació I Experimentació Marítima (CIEM), at the Universitat Politècnica de Catalunya (Barcelona, Spain). The flume is $100.0 \mathrm{~m}$ long, $3.0 \mathrm{~m}$ wide, $4.5 \mathrm{~m}$ deep and is equipped with a wedge type wave generator (Figure 2).

Two structures have been tested in the wave flume: a vertical quay wall (Figure 3, upper panel) and a smooth dike slope (Figure 3, lower panel). A scale of $1 / 6$ has been selected to size the model taking as reference typical dimensions of coastal structures along the Belgian coast. The total height of the structures, measured from the top of the $0.90 \mathrm{~m}$ thick sand layer which was present in the flume and acted as a foreshore, is $1.82 \mathrm{~m}$ (10.92 $\mathrm{m}$ in prototype). Three water levels have been used, resulting in freeboards (measured from the water level to the level of the structure crest, not considering the storm wall; ' $\mathrm{A}_{\mathrm{c}}$ ' according to the definition of the Neural Network for wave overtopping) of $0.33,0.17$ and $0.0 \mathrm{~m}$ model scale values. 
Tests have been carried out with and without the storm wall on the promenade. The former had the aim of measuring impact forces and pressures on the storm wall, and wave overtopping over the storm wall; the latter was designed to measure the overtopping discharge without storm wall, and measure unreflected and undisturbed flow depths and flow velocities of the overtopping bore on the promenade. These however, will not be treated in this paper.

The storm wall is located at $1.69 \mathrm{~m}$ (10.14 $\mathrm{m}$ in prototype) behind the crest of the structure, creating a promenade between the structure's crest and the storm wall (see Figure 3). The height of the storm wall is $0.20 \mathrm{~m}$ (1.20 m in prototype), giving a freeboard $R_{c}$ from the still water level to the top of the storm wall of $0.53,0.37$ and $0.20 \mathrm{~m}$ (model values) respectively. The storm wall has been built to cover the entire width of the flume, but in different panels. All panels of the storm wall have been aligned in one vertical plane. One panel (width of $0.5 \mathrm{~m}$ ) has been instrumented to measure the impact forces. In total 4 load cells have been fixed to a rigid supporting structure and the panel was attached to these sensors (see Figure 5). Another panel has been firmly fixed to the supporting structure and 3 holes for the pressure sensors have been prepared, aligned along a vertical line (see Figure 4). The positions of the center of the sensors, from the base of the storm wall, are $2.5 \mathrm{~cm}, 10 \mathrm{~cm}$ and $17.5 \mathrm{~cm}$.

The instruments that have been deployed during the experimental tests are listed here, namely:

- 12 resistive wave gauges placed along the wave flume have been used to record the free surface elevation time series;

- 4 acoustic wave gauges and 4 acoustic Doppler velocimeters placed on the top of the structure have been used to measure respectively the flow depth and the flow velocity of the overtopped bore on the promenade;

- 4 load cells and 3 pressure sensors have been placed on 2 different plates of the storm wall to measure the forces and pressures acting on it;

- 2 cameras have been installed, one looking from the front towards the structure, the other looking from the backside to the top of the crest, to film the experiments.

The wave conditions reproduced in the flume were irregular time series following a Jonswap spectrum $(\gamma=3.3)$. As stated earlier, 3 different water levels $h$, measured at the wave maker location, have been considered $(\mathrm{h}=2.39 \mathrm{~m}, 2.55 \mathrm{~m}, 2.72$ $\mathrm{m}$, height related to the bottom of the flume). The significant wave height $\mathrm{H}_{\mathrm{m} 0}$ ranges from $0.13 \mathrm{~m}$ to $0.50 \mathrm{~m}$, the wave period $\mathrm{T}_{\mathrm{p}}$ is either $2.86 \mathrm{~s}$ or $4.08 \mathrm{~s}$ (note that these wave conditions can be classified according to the EurOtop as "non-breaking waves”).

The total number of experimental tests is 53, of which 32 valid tests with impacts on a storm wall. Finally, it is worth to cite that the input free surface elevation time series has been created long enough to contain more or less 1,000 waves. The test matrix is shown in Table 1. 


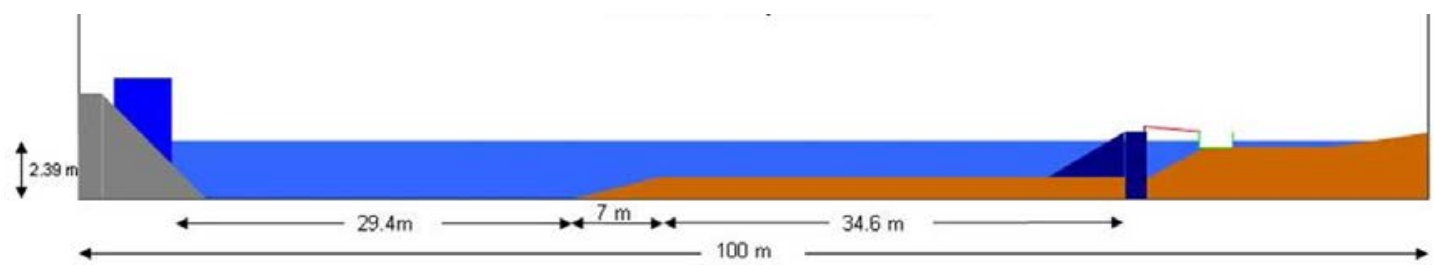

Figure 2. Sketch of the wave flume and of the tested structure
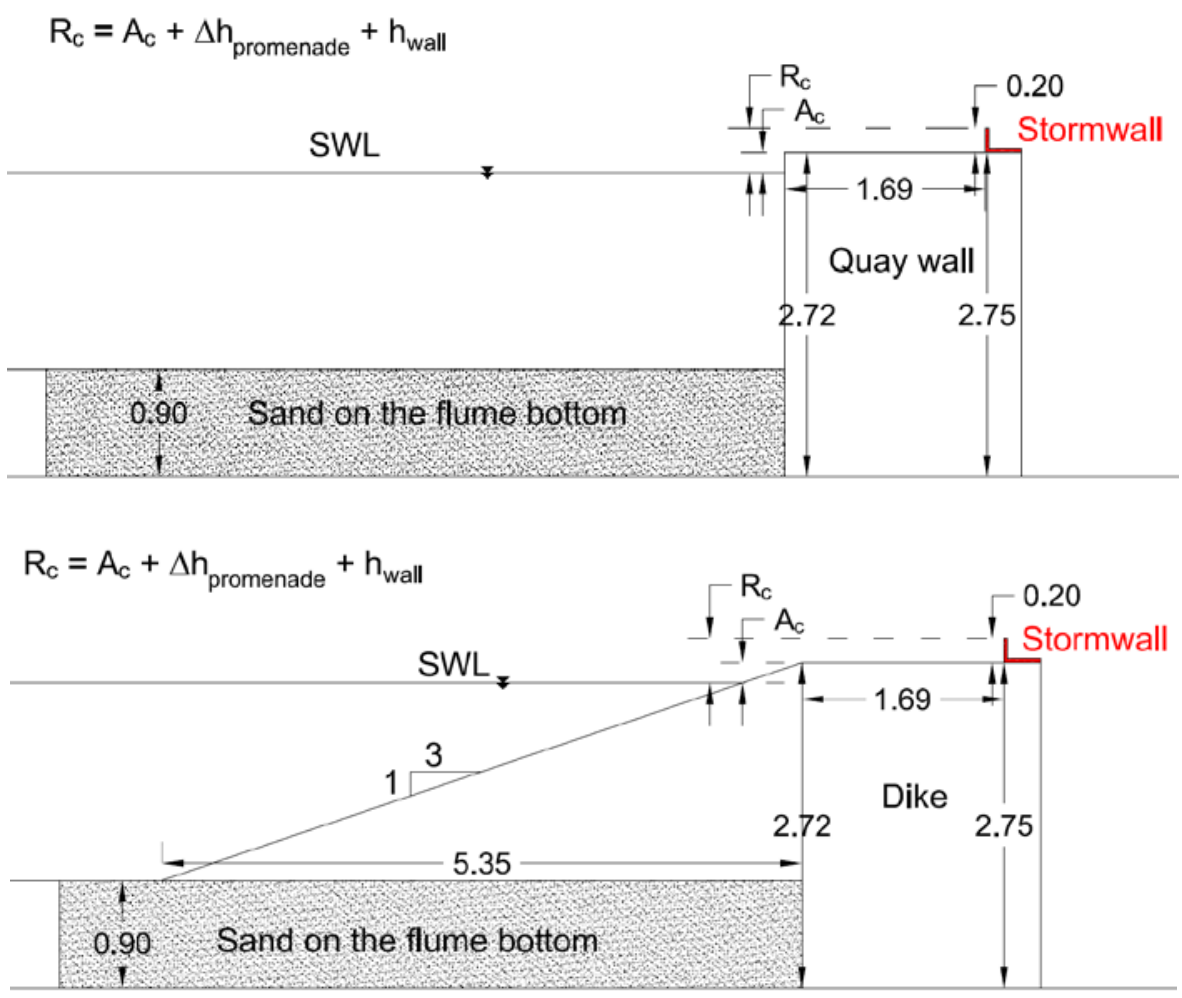

Figure 3. Sketch of the quay wall and dike geometries with a promenade and a storm wall (sea side/wave paddle side on the left, impacts on the right)

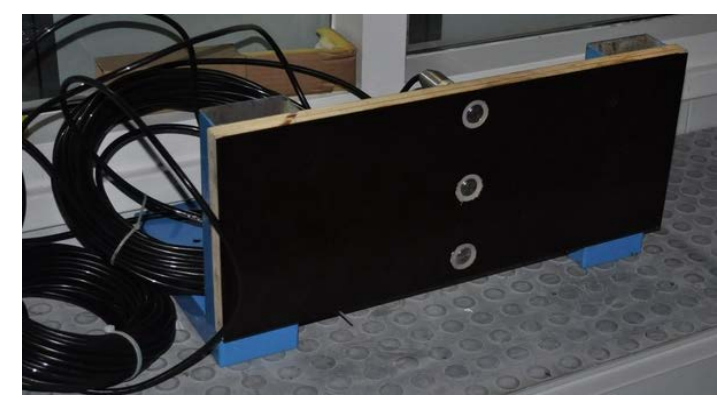

Figure 4. Detail of the storm wall with pressure transducers (before installation)

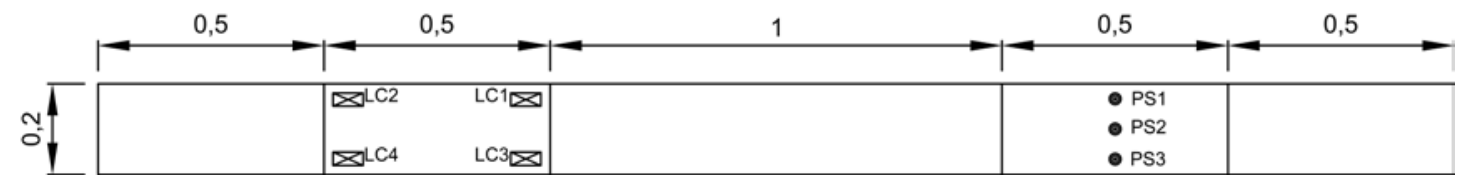

Figure 5. Sketch of the storm wall. Note: positions and names of the load cells and pressure transducers are represented 
Table 1. test conditions at CIEM laboratory (model scale values)

\begin{tabular}{|c|c|c|c|c|}
\hline & & & quay wall & dike \\
\hline Number of impact tests & - & & 18 & 14 \\
\hline Wave spectrum & - & & Jonswap 3.3 & Jonswap 3.3 \\
\hline Seaward crest height ${ }^{1}$ & - & (m) & 2.72 & 2.72 \\
\hline Promenade width $^{2}$ & B & (m) & 1.69 & 1.69 \\
\hline Promenade slope & - & (\%) & 1.8 & 1.8 \\
\hline height storm wall & $h_{\text {wall }}$ & (m) & 0.20 & 0.20 \\
\hline Landward crest height & - & (m) & 2.95 & 2.95 \\
\hline Wave height & $\mathrm{H}_{\mathrm{m} 0}$ & (m) & $0.13-0.50$ & $0.25-0.50$ \\
\hline Wave period & $\mathrm{T}_{\mathrm{p}}$ & (s) & $2.86 ; 4.08$ & $2.86 ; 4.08$ \\
\hline Water depth ${ }^{1}$ & $\mathrm{~h}$ & (m) & $2.39 ; 2.55 ; 2.72$ & $2.39 ; 2.55 ; 2.72$ \\
\hline Freeboard (seaward side) & $A_{c}$ & (m) & $0.33 ; 0.17 ; 0$ & $0.33 ; 0.17 ; 0$ \\
\hline Freeboard (landward side, incl. stormwall) & $\mathrm{R}_{\mathrm{c}}$ & (m) & $0.56 ; 0.40 ; 0.23$ & $0.56 ; 0.40 ; 0.23$ \\
\hline Dimensionless freeboard (seaward side) & $\mathrm{A}_{\mathrm{c}} / \mathrm{H}_{\mathrm{m} 0}$ & $(-)$ & $0-0.76$ & $0-1.24$ \\
\hline Dimensionless freeboard (landward side) & $\mathrm{R}_{\mathrm{c}} / \mathrm{H}_{\mathrm{m} 0}$ & $(-)$ & $0.45-2.27$ & $0.64-2.10$ \\
\hline
\end{tabular}

\section{ANALYSIS AND RESULTS}

In this section the data analysis techniques and an overview of the results are presented. It is structured as follows: first the wave reflection analysis is briefly described, then the forces and pressures data measured on the storm wall are presented and discussed. In the end, some relationships between impact forces and hydraulic parameters $\left(\mathrm{A}_{\mathrm{c}}, \mathrm{R}_{\mathrm{c}}, \mathrm{H}_{\mathrm{m} 0}\right)$ are proposed.

The free surface elevation time series have been collected by using 12 resistive wave gauges placed along the wave flume. The measured signals have been analyzed in order to obtain the effective wave conditions generated in the flume (i.e. incident significant wave height $\mathrm{H}_{\mathrm{m} 0}$ ). The reflection analysis methods described by Goda \& Suzuki (1976) and Mansard \& Funke (1980) have been applied by using respectively 2 and 3 wave gauges (i.e. the closest to the tested structure, but always more than $40 \%$ of the wavelength away from the structure). The two reflection analysis have provided similar results, thus the incident significant wave heights obtained by the method of Mansard \& Funke (1980), based on 3 gauges, is used.

As previously mentioned both load cells and pressure gauges have been deployed for measuring the forces on the storm walls. Since load cells measure the response of a structure to the impact load, it is useful to estimate the eigenfrequencies of the tested structure to characterize the response of the model itself in the frequency domain. Thus, a "hammer test" has been carried out: the storm wall has been hammered aiming at analyzing the free oscillations. Figure 6 shows the force time series recorded during this test; The figure clearly shows four different hits (or impacts). Each impact has been identified within the signal and has been analyzed in the frequency domain by means of a Fourier analysis. The normalized spectral densities are represented in Figure 7. It is worth noticing that the four normalized

1 distance to the bottom of the flume

2 In the longitudinal direction of the flume (distance between seaward crest and storm wall) 
spectral densities (from the four hits) are almost perfectly on top of each other in this graph. It shows that the lowest eigenfrequency is equal to $88.0 \mathrm{~Hz}$, while the wave impact frequencies are between 0 and $10 \mathrm{~Hz}$. Thus, it can be stated that the eigenfrequencies are quite larger than the wave impact frequencies reproduced during the tests, and no resonance is to be expected.
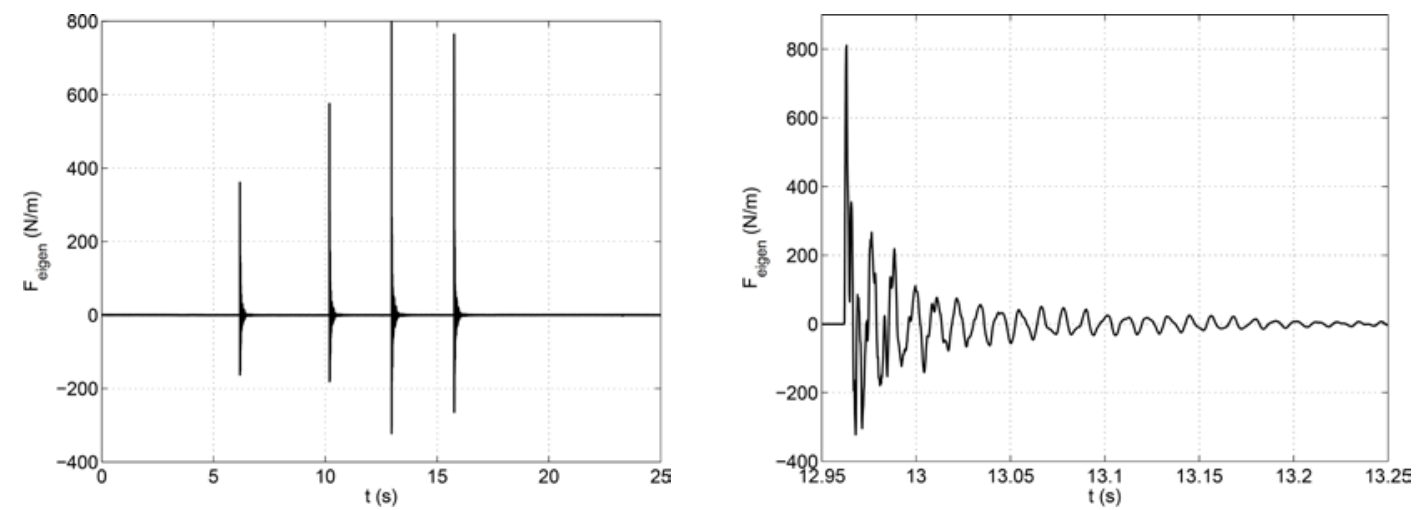

Figure 6. Left panel: force time series measured during the "hammer test". Right panel: zoom of the third hammer hit

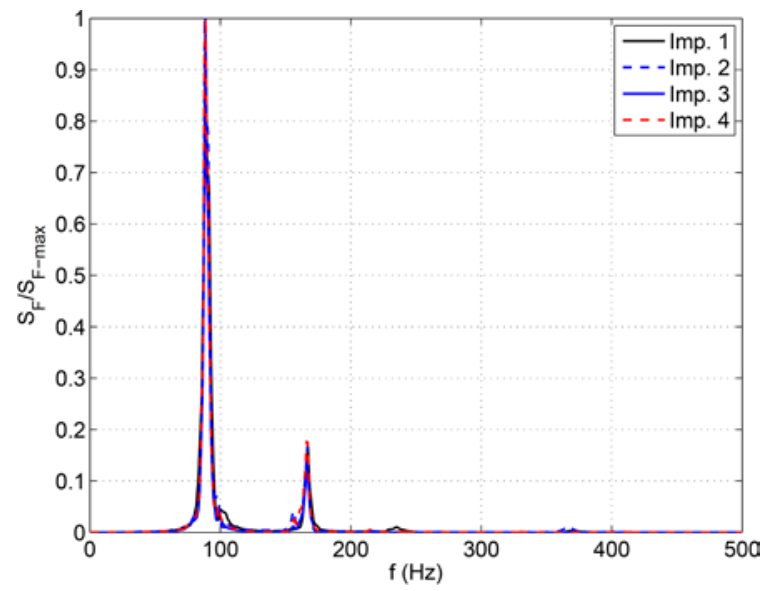

Figure 7. Normalized spectral densities of the recorded "hammer hit" as a function of the frequency

Furthermore, due to that both direct forces and pressures have been measured at the storm wall, it is important to cross-check the agreement between these two measurement systems. Total forces induced by the overtopping waves on the storm wall have been obtained directly from the force sensors and indirectly by integrating the simultaneous pressure records. The forces measured by the load cells have been summed up and divided by the width of the plate $(0.50 \mathrm{~m})$ in order to determine the total forces per running meter acting on the storm wall $(\mathrm{N} / \mathrm{m})$. To obtain the total forces $(\mathrm{N} / \mathrm{m})$ from the pressure measurements a rectangular integration method has been used. A comparison of integrated pressures and simultaneously measured forces using force transducers can provide an assessment of the validity of the pressure integration. Figure 8 shows a comparison between the total forces obtained by both the direct measurements (i.e. load cells; black lines in the plots) and by the indirect 
ones (i.e. pressure sensors; red lines in the plots) during one representative test. The force distribution over the time is in good agreement with the integrated pressures including the peak values, as was also the case in De Rouck et al. (2012). Both pressure and force sensors recorded a double peak profile. Most of the recordings are in line with the church roof shape as described in the literature (Oumeraci et al., 2001). The first peak corresponds to the dynamic component of the impact load, and the second peak to the quasi-static component. However, for some events, it was noticed that the second peak was the higher peak. The incoming bore pushes the residual water layer (often still present at the promenade from a previous impact) against the storm wall, and shortly after it impacts the storm wall itself. Video analysis is necessary at the moments of those impacts, but the residual water later which was still present from the previous impact will largely affect this result and account for the difference of the recording in comparison with the typical church roof profile from literature (which is related to high vertical walls or storm walls located at the waterfront of a structure, with direct wave impact, which is different from a bore hitting a landward wall).
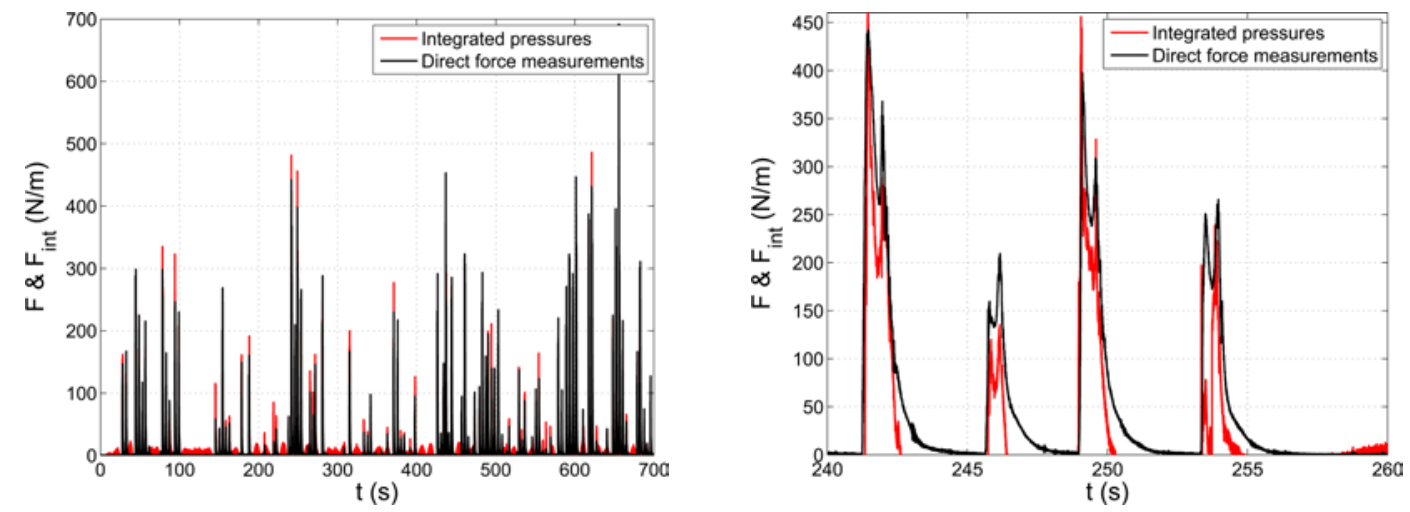

Figure 8. Comparison between the integrated pressures (red lines) and the simultaneously measured forces (black lines) for the test 2013_07_31_0.
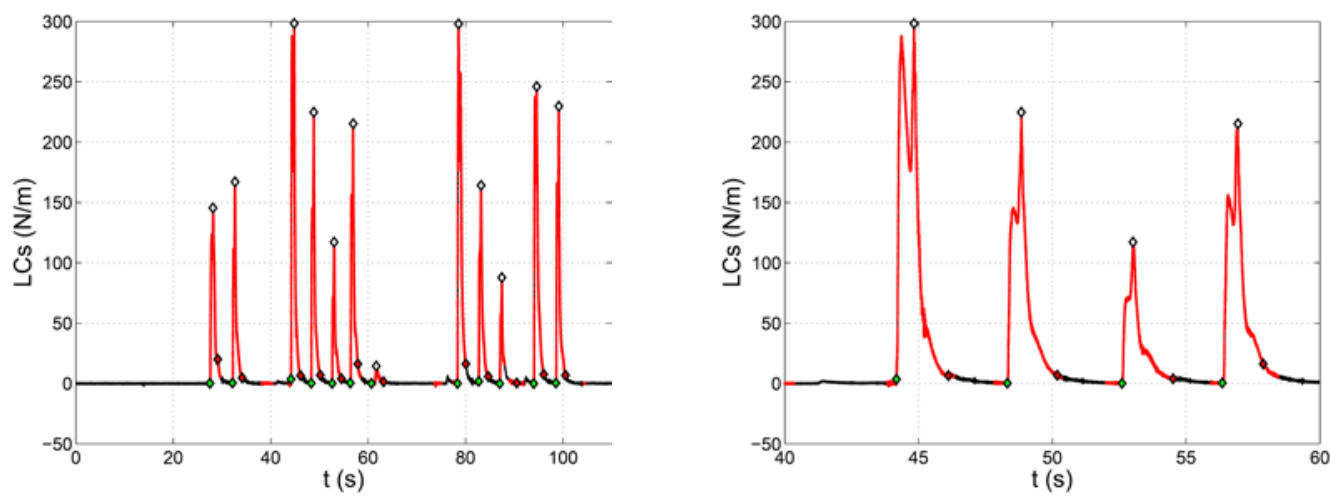

Figure 9. Example of the peak impact detection (test 2013_07_31_0); the white diamond markers refer to the maximum peak value of each event, while the red lines identify the whole events.

In order to provide a detailed analysis of the total forces acting on the storm wall an in-depth study of the single peak impacts has been carried out. An automatic 
algorithm has been developed to identify each force impact that exceeds the threshold of $4 \mathrm{~N} / \mathrm{m}$ (with this value, all impacts were considered). An example of the detection procedure is given in Figure 9. The figure shows that the algorithm allows to obtain not only the maximum value of the impact event, but also the duration and the shape of the event itself. This can be very important given that a detailed analysis of the shape of the peak impacts will be performed in the future. The peak impacts that occur at the storm wall, detected by the algorithm, have been identified for each experimental test. Given this, it is possible to obtain, for each experiment, the distribution and several statistical parameters that are of interest to describe quantitatively the features of the forces that act on the storm wall. These parameter (e.g., $F_{1 / 3}, F_{1 / 250}, F_{\max }$, etc.) can be linked to the wave parameters and the flow depth/velocity field on the promenade. The aim of this comparison is to provide an engineering predictive formula/method for estimating the loads at the storm wall given the geometry of the structure and the incoming wave conditions.

The conditions that have an influence on the impacts are quite numerous. First, the hydraulic conditions (freeboard $\mathrm{A}_{c}$, wave height $\mathrm{H}_{\mathrm{m} 0}$ ), which also determine the average overtopping discharge $q$ which arrives at the promenade. Second, the individual overtopping volumes, each with a flow depth, flow velocity and their time duration per overtopped wave. Next, there is some energy loss due to the promenade's width, the friction on the slope and/or promenade and the overtopping over the (height of the) storm wall. At last, some not very well known factors such as the seeding number used for the generation of the input waves time series, which may create different wave groups and thereby having an influence on the impacts. The turbulence of the water layer shows that is a stochastic process. And the possible presence (and thickness) of the residual water layer also can have its effect on the impact.

For now, only the relationship between impacts and wave conditions is discussed. The other effects are still being analyzed and will be presented in the future. Note that the results are thereby only valid on this geometry and within the parameter range as presented in Table 1.

After having analyzed all impacts (above threshold value $4 \mathrm{~N} / \mathrm{m}$ ) per test, statistical analysis of the peak forces sample has shown they can be well represented by a two parameter Weibull probability density function. For all tests analyzed, the general shape parameters are $\kappa=1.05$ (shape parameter) and $\lambda=109.54$ (scale parameter). Note that we have only selected the upper $30 \%$ of the impacts, since for design purposes we are mainly interested in the highest impacts.

An empirical relationship between $F_{\max }$ and other statistical values like $F_{1 / 250}$ (the average force of the highest $1 / 250$ waves) and $F_{1 / 3}$ (the average force of the highest $1 / 3$ waves) was deducted from the data. Mean values are given, with standard deviation between brackets.

$$
F_{\max }=1.23( \pm 0.03) F_{1 / 250}=3.98( \pm 0.20) F_{1 / 3}
$$

The impacts on the storm wall have a dependency on the hydraulic parameters. For the wave height, it is quite clear: higher waves lead to higher maximum impacts on the storm wall. However, it can be supposed that this 
increasing trend deflects after a certain value. For example, when the crest freeboard $A_{c}$ is very high (waves hardly or not reach the structure) or when the total freeboard $\mathrm{R}_{\mathrm{c}}$ is very low (a lot of energy dissipation by overtopping over the storm wall, causing a smaller increase in impact forces). This already rises the impression that $H_{m 0}$ and $A_{c}$ or $R_{c}$ have a connected influence on the impact. Note that in our tests, $\mathrm{R}_{\mathrm{c}}=\mathrm{A}_{\mathrm{c}}+\Delta \mathrm{h}_{\text {promenade }}+\mathrm{h}_{\text {wall }}=\mathrm{A}_{\mathrm{c}}+$ constant.

For very small freeboards $R_{c}$, lots of wave overtopping over the storm wall occurs and the effect of the freeboard on the impacts on the storm wall is relatively small, also in view of the thick water layer in front of the wall. For very high freeboards $A_{c}$, waves might not even reach the storm wall. In the range between, there is a maximum. A parabolic trend is expected.

When plotting the data of $F$ versus $\mathrm{R}_{\mathrm{c}} / \mathrm{H}_{\mathrm{m} 0}$, a quite large scatter results, regardless which statistical parameter $\left(\mathrm{F}_{\max }, \mathrm{F}_{1 / 250}, \ldots\right)$ is plotted. This is reduced by making the force dimensionless, i.e. dividing it by $\rho \cdot g \cdot \mathrm{R}_{\mathrm{c}}{ }^{2}$ (which is the hydrostatic force given by water from SWL up to the crest level), as reported in Figure 10. Now, data are used to derive the coefficients of an exponential function of the form

$$
F=a \cdot \rho \cdot g \cdot R_{c}^{2} \cdot \exp \left(-b \cdot \frac{R_{c}}{H_{m 0}}\right)
$$

Non-linear regression analysis leads to the coefficients in Table 2, to be considered as the mean value of a normal distribution. Between brackets, the relative standard deviation $\left(\sigma^{\prime}=\sigma / \mu\right)$ for each coefficient is reported.

Table 2. coefficients a and $b$ from equation [2] for different geometries and different statistical parameters.

\begin{tabular}{l|cc|cc}
\multicolumn{2}{c}{$\mathrm{F}_{1 / 250}$} & \multicolumn{2}{c}{$\mathrm{F}_{\max }$} \\
Geometry & $\mathrm{a}$ & $\mathrm{b}$ & $\mathrm{a}$ & $\mathrm{b}$ \\
\hline Dike & $8.31(0.22)$ & $2.45(0.07)$ & $11.06(0.23)$ & $2.50(0.07)$ \\
Quay wall & $18.27(0.23)$ & $3.99(0.06)$ & $23.48(0.24)$ & $4.10(0.06)$ \\
All tests & $5.96(0.23)$ & $2.42(0.09)$ & $7.27(0.25)$ & $2.44(0.09)$ \\
\hline
\end{tabular}

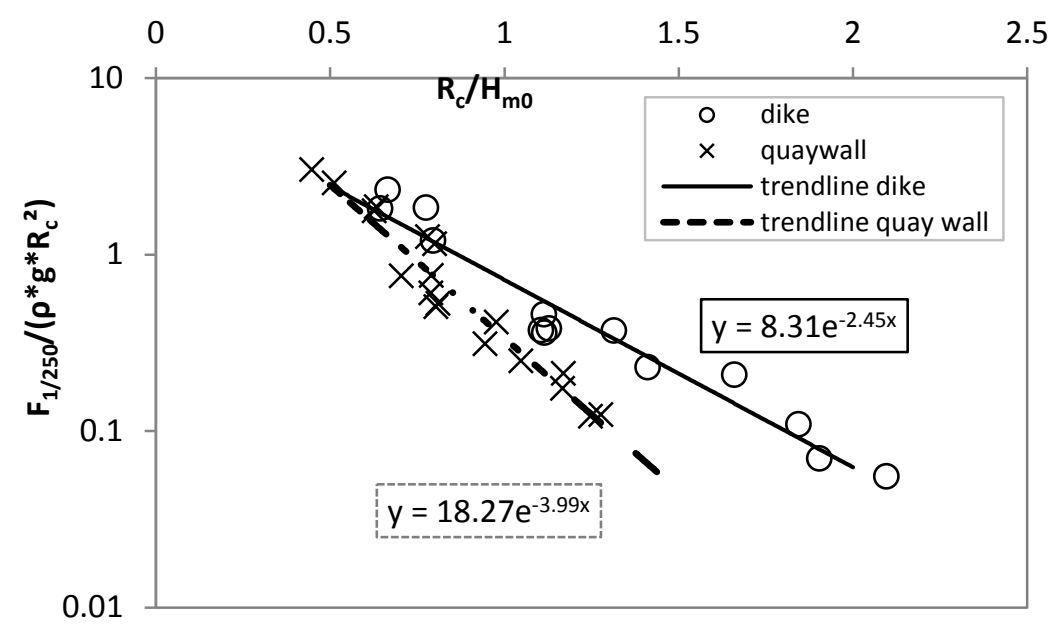

Figure 10. Dimensionless force vs dimensionless $\mathbf{R}_{c}$ freeboard, semilogarithmic

If relationship [2] is plotted with varying freeboard or wave height $\mathrm{H}_{\mathrm{m} 0}$, we obtain the graph reported in Figure 11, which shows the expected relationship 
between $\mathrm{F}$ and the hydraulic parameters. The solid lines are the ranges in which data are available, which confirm this shape. The dotted lines are theoretical extrapolations of how the data might look like, yet unconfirmed at this stage due to missing data.

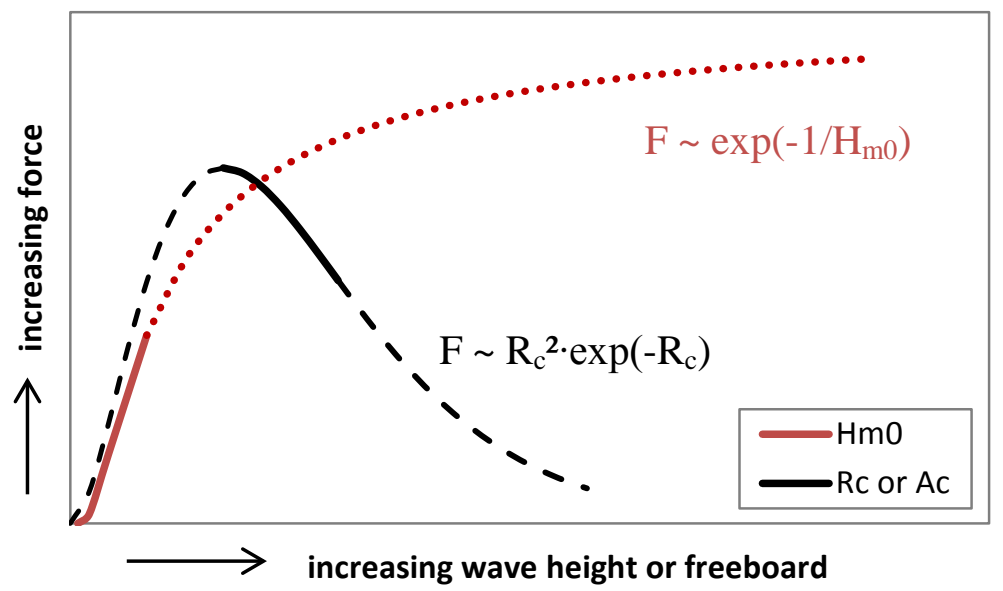

Figure 11. Generic influence of increasing $H_{m 0}$ (black line) and $R_{c}$ (red line) on the force $F$

Although Figure 10 gave a low scattered relationship between the impact force and the main hydraulic parameters $R_{c}$ and $H_{m 0}$, it makes sense to plot $A_{c} / H_{m 0}$ on the horizontal axis, because that value is directly related to the wave overtopping which arrives at the promenade and causes the impacts. For the major part of the data, the correlation looks promising, but further analysis needs to be carried out to come up with a less scattered equation for values with $A_{c}=0$.

$$
F=a \cdot \rho \cdot g \cdot R_{c}^{2} \cdot \exp \left(-b \cdot \frac{A_{c}}{H_{m 0}}\right)
$$

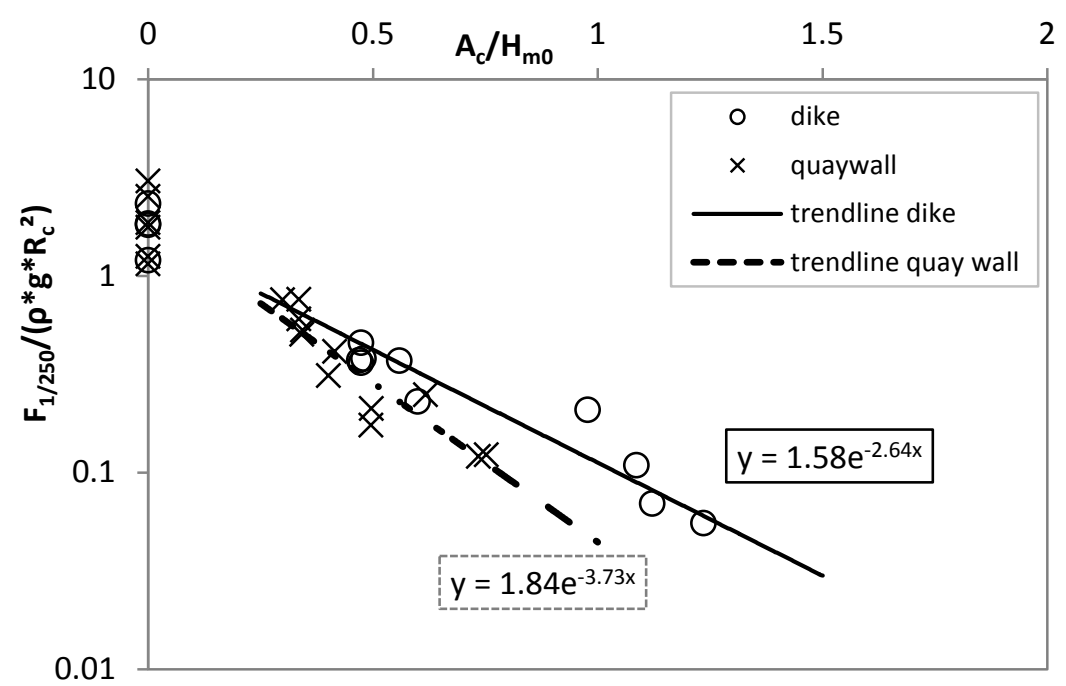

Figure 12. Dimensionless force vs dimensionless $A_{c}$ freeboard, semilogarithmic

Non-linear regression analysis lead to the coefficients in Table 3 (mean values with their relative standard deviations between brackets); it is advised to only use these values for $\mathrm{A}_{\mathrm{c}} / \mathrm{H}_{\mathrm{m} 0}$ between 0.25 and 1.25. 
Table 3. Coefficients a and b from equation [3] for different geometries and different statistical parameters.

\begin{tabular}{l|cc|cc}
\multicolumn{2}{c}{$\mathrm{F}_{1 / 250}$} & \multicolumn{2}{c}{$\mathrm{F}_{\max }$} \\
Geometry & $\mathrm{a}$ & $\mathrm{b}$ & $\mathrm{a}$ & $\mathrm{b}$ \\
\hline Dike & $1.58(0.12)$ & $2.64(0.07)$ & $1.99(0.15)$ & $2.66(0.08)$ \\
Quay wall & $1.84(0.11)$ & $3.73(0.08)$ & $2.19(0.13)$ & $3.78(0.09)$ \\
All tests & $1.57(0.10)$ & $2.87(0.06)$ & $1.88(0.11)$ & $2.87(0.07)$ \\
\hline
\end{tabular}

Based on Figure 10, we can conclude the selected hydraulic parameters $\left(R_{c}\right.$, $\mathrm{H}_{\mathrm{m} 0}$ ) are quite robust variables for building a low-scattered relationship to estimate the impact forces, but these parameters alone are not enough to describe the whole process. Post-overtopping parameters such as flow depths, flow velocities and individual overtopping volumes over the crest of the dike/quay wall, as well as the width, permeability and roughness of the promenade also are expected to have a strong influence on this process. Some data points with small wave period have not yet been included in this analysis, since they are not fully in line with other tests, which might show a dependency on the wave period. This will be further investigated.

For the design of structures, one is interested in the highest force to be expected. However, $F_{\max }$ is a more scattered parameter than other statistical (averaged) parameters such as $\mathrm{F}_{1 / 250}, \mathrm{~F}_{1 / 100}, \mathrm{~F}_{1 / 3}$, etc. This shows from the standard deviations of the coefficients reported in Table 2 and 3, which are up to $50 \%$ higher for $\mathrm{F}_{\max }$ than for $\mathrm{F}_{1 / 250}$.

Recently it was shown for wave overtopping data (e.g. Romano et al., 2015) that the seeding number variation can cause variation in the results, certainly in terms of maximum values (i.e. $F_{\max }$ ). Next to this, visual observations during the tests showed that the overtopping bore on the promenade is a highly turbulent and stochastic phenomenon. This also causes some scatter, more on the maximum values than on other (averaged) values. Nevertheless, values for both $F_{\max }$ and $F_{1 / 250}$ are given in this paper to be used inside the studied range of parameters, with the message that a formula for $F_{1 / 250}$ is more robust and less scattered than $F_{\max }$.

The outlook of this paper brings us to scale and model effects on impacts. Besides the tests in the Hydralab framework (scale 1/6), other test campaigns on similar geometries have been carried out in the recent past, guided by Ghent University, going from large scale (1/1 to $1 / 2)$ to small scale (1/15 to $1 / 20)$, see Van Doorslaer et al. (2012). The results of all tests campaigns will be compared to each other. It is known that small scale tests have less air entrainment which would result in larger (upscaled) forces in comparison with large scale and prototype tests with much more entrained air in the turbulent overtopped bore.

\section{CONCLUDING REMARKS AND ONGOING RESEARCH}

This paper has presented the aims of the new experimental campaign carried out in the large wave flume (CIEM) in Barcelona. A brief overview of the experimental set-up and methodology of analysis is given and first results, aimed at 
calculating the impact forces on the basis of the hydraulic parameters $A_{c}, R_{c}$ and $H_{m} 0$ are presented.

Analysis is ongoing to relate the impact forces also to the post-overtopping parameters such as flow depth and flow velocity on the promenade.

In a later stage, the recorded forces will also be compared with available small scale (1/20) laboratory tests carried out at the University of Ghent, Belgium (Van Doorslaer et al, 2012) and with large scale tests (scale 1/1) performed at GWK in Hannover, Germany (De Rouck et al, 2012) to investigate scale effects.

\section{ACKNOWLEDGEMENT}

This work has been supported by European Community's Seventh Framework Program through the grant to the budget of the Integrating Activity HYDRALAB IV within the Transnational Access Activities, Contract no. 261520.

\section{REFERENCES}

Chen, X., Hofland, B., Altomare, C., Suzuki, T., Uijttewaal, W. 2015. Forces on a vertical wall on a dike crest due to overtopping flow. Coastal Engineering 95, 94-104

De Rouck, J., Van Doorslaer, K., Versluys, T., Ramachandran, K., Schimmels, S., Kudella, M., Trouw, K. 2012. Full Scale Wave Impact Tests on a Vertical Wall in the Large Wave Flume (GWK) in Hannover. Proceedings of ICCE 2012, Santander, Spain.

Goda Y. and Suzuki, T. 1976. Estimation of incident and reflected waves in random wave experiments, Proceedings of ICCE 1976, Honolulu, 17pp.

Mansard E.P.D. and Funke, E.R. 1980. The measurement of incident and reflected spectra using a least squares method, Proceedings of ICCE 1980, Sidney, 18pp.

Oumeraci H., Kortenhaus A., Allsop N.W.H., De Groot M.B., Crouch R.S., Vrijling J.K. and Voortman H.G. 2001. Probabilistic design tools for vertical breakwaters, Rotterdam, The Netherlands: Balkema, 392pp.

Pullen T., Allsop N.W.H., Bruce T., Kortenhaus A., Schüttrumpf H. and van der Meer J. 2007. EurOtop - Wave Overtopping of Sea Defences and Related Structures Assessment Manual, Environmental Agency UK, 193pp.

van der Meer J.W., Hardeman B., Steendam G.J., Schüttrumpf H. and Verheij H. 2010. Flow depths and velocities at crest and landward slope of a dike, in theory and with the wave overtopping simulator, Proceedings of ICCE 2010, Shangai, 193pp.

Van Doorslaer K., De Rouck J., Trouw K., van der Meer J. and Schimmels S. 2012. Wave forces on storm walls, small and large scale experiments, Proceedings of COPEDEC VIII, Chennai, 11pp.

Romano, A., Bellotti, G., Briganti, R., Franco, L., 2015. Uncertainties in the physical modelling of the wave overtopping over a rubble mound breakwater: The role of the seeding number and of the test duration. Coastal Engineering 103, 15 21. 